Review

\title{
DLG5 in Cell Polarity Maintenance and Cancer Development
}

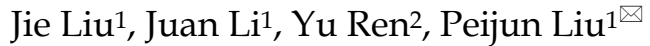 \\ 1. Center for Translational Medicine, the First Affiliated Hospital of Xian Jiaotong University College of Medicine; \\ 2. Department of Surgical Oncology, the First Affiliated Hospital of Xian Jiaotong University College of Medicine.
}

$\triangle$ Corresponding author: Peijun Liu, Ph.D.\&M.D., Professor, Email: liupeijun@mail.xjtu.edu.cn, Tel: 086-18991232306, Address: 277 Yanta Western Rd., Xi'an, Shaan Xi Province, China, 710061.

(c) Ivyspring International Publisher. This is an open-access article distributed under the terms of the Creative Commons License (http://creativecommons.org/ licenses/by-nc-nd/3.0/). Reproduction is permitted for personal, noncommercial use, provided that the article is in whole, unmodified, and properly cited.

Received: 2014.02.19; Accepted: 2014.04.17; Published: 2014.05.03

\begin{abstract}
Failure in establishment and maintenance of epithelial cell polarity contributes to tumorigenesis. Loss of expression and function of cell polarity proteins is directly related to epithelial cell polarity maintenance. The polarity protein discs large homolog 5 (DLG5) belongs to a family of molecular scaffolding proteins called Membrane Associated Guanylate Kinases (MAGUKs). As the other family members, DLG5 contains the multi-PDZ, SH3 and GUK domains. DLG5 has evolved in the same manner as DLGI and ZOI, two well-studied MAGUKs proteins. Just like DLGI and ZOI, DLG5 plays a role in cell migration, cell adhesion, precursor cell division, cell proliferation, epithelial cell polarity maintenance, and transmission of extracellular signals to the membrane and cytoskeleton. Since the roles of DLG5 in inflammatory bowel disease (IBD) and Crohn's disease $(C D)$ have been reviewed, here, our review focuses on the roles of DLG5 in epithelial cell polarity maintenance and cancer development.
\end{abstract}

Key words: DLG5, epithelial cell polarity, EMT, cell proliferation, migration.

\section{Introduction}

The establishment and maintenance of epithelial cell polarity is crucial for maintaining epithelial integrity. Epithelial cell polarity maintenance mainly depends on cell polarity complexes and cell adhesion complexes (Table 1). Three major polarity complexes have been identified. The PAR complex, formed by PAR3, PAR6, atypical protein kinase $\mathrm{C}$ (aPKC, PKCל and $\mathrm{PKC} \mathrm{i}$ in humans) and cell division control protein 42 (CDC42), is required for maintenance of apical-lateral polarity. The crumbs (CRB) complex participates in establishment of the apical membrane and comprises transmembrane protein CRB, cytoplasmic protein PALS1 and PALS1-associated tight junction protein (PATJ). The scribble (SCRIB)-LETHAL (2) giant larvae homologue (LGL)-discs large homologue (DLG) complex (SCRIB-LGL-DLG complex) maintains the basolateral plasma membrane domain [1]. Cell adhesion complexes consist of adherens junc- tional complexes and tight junctional complexes. Cadherin-catenin and nectin-afadin complexes are two adherens junctional complexes and occur at the core of the adherens junction (AJ) [2]. The tight junctional complexes are composed of zonula occludens (ZO) subfamily, occludin, claudin and junctional adhesion molecules (JAM) [3]. Loss of cell polarity complexes and adhesion complexes lead to failure in maintenance of epithelial cell polarity, inducing epithelial-to-mesenchymal transition (EMT), cell hyperproliferation and enhanced cell invasive potential [4-7].

Membrane Associated Guanylate Kinases (MAGUKs) are a family of proteins that contain multi-PDZ domains, a Src homology 3 ( SH3) domain and a guanylate kinase (GUK) domain [8]. According to their different phylogenetic positions and domain architectures, MAGUKs are classified into 10 sub- 
types: discs large homolog 1 (DLG1/SAP-97, DLG2-4), calcium/calmodulin-dependent protein kinase (CASK), membrane palmitoylated protein 1 (MPP1, P55), MPP5, MPP2-7, zona occludens (ZO, TJP), DLG5, caspase recruitment domain-containing MAGUK protein (CARMA), voltage-dependent L-type calcium channel $\beta$-subunit (CACNB), and membrane-associated guanylate kinase inverted 1-3 (MAGI1-3) [9-11] (Fig. 1, Table 2). MAGUKs act as key scaffolds at cell membranes for protein complexes containing several receptors and various signaling molecules. MAGUKs also play significant roles in cell adhesion and tight junction [12]. DLG1 and ZO1, typical members of MAGUKs, participate in establishment and maintenance of apical-basal polarity of epithelia cells [13]. DLG1, also a component of the SCRIB-LGL-DLG polarity protein complex, functions as a tumor suppressor in mammals [14-16] and affect cell division [17]. ZO1 participates in establishment of the belt-like adherens and tight junctions [18] and its expression decreases in transmigratory cancer cells [19].

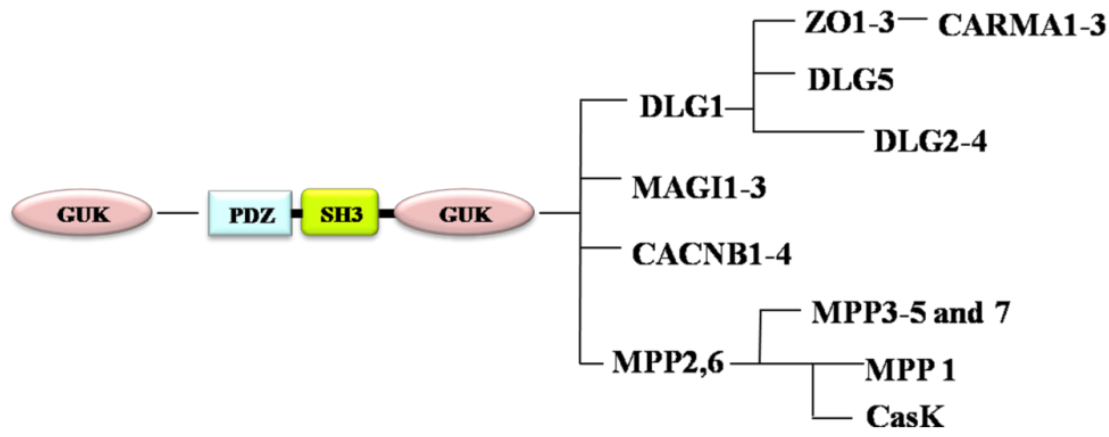

Figure I. Evolution of MAGUK family.

Table I. Cell polarity complexes and cell adhesion complexes.

\begin{tabular}{|c|c|c|c|c|}
\hline & Complex & Components & Function & Ref. \\
\hline \multirow[t]{3}{*}{$\begin{array}{l}\text { Cell polarity } \\
\text { complexes }\end{array}$} & PAR complex & $\begin{array}{l}\text { PAR3, PAR6, aPKC (PKC } 3 \text { and PKC } \mathrm{P} \text { in humans) } \\
\text { and CDC42 }\end{array}$ & Maintenance of apical-lateral polarity & [1] \\
\hline & Crumbs complex & CRB, PALS1 and PATJ & Establishment of the apical plasma membrane & \\
\hline & SCRIB complex & Scribble, LGL and DLG & Maintenance of the basolateral membrane & \\
\hline \multirow[t]{2}{*}{$\begin{array}{l}\text { Cell adhesion } \\
\text { complexes }\end{array}$} & $\begin{array}{l}\text { Adherens junctional com- } \\
\text { plexes }\end{array}$ & $\begin{array}{l}\text { Cadherin-catenin, nectin-afadin } \\
\text { complexes, etc. }\end{array}$ & Adherens junction & [2] \\
\hline & Tight junctional complex & ZO subfamily, occludin, claudin and JAM & Tight junction & [3] \\
\hline
\end{tabular}

Table 2. MAGUKs, their functions and involvement in diseases

\begin{tabular}{|c|c|c|c|}
\hline Name & Functions & Disease & Ref. \\
\hline$\overline{D L G}$ & $\begin{array}{l}\text { Maintenance of cell polarity, cell proliferation, migration and } \\
\text { adhesion, cell division, synapse formation. }\end{array}$ & $\begin{array}{l}\text { Breast, cervical and clolon cancer, kidney disease } \\
\text { and renal failure, schizophrenia, etc. }\end{array}$ & {$[23,33,59-61]$} \\
\hline CASK & $\begin{array}{l}\text { Maintenance of cell polarity, progenitor population, synapse } \\
\text { formation, cell migration. }\end{array}$ & $\begin{array}{l}\text { Kidney disease and renal failure, nystagmus, } \\
\text { Ohtahara syndrome and cerebellar } \\
\text { hypoplasia, Pontocerebellar hypoplasia, etc. }\end{array}$ & {$[12,23,61]$} \\
\hline MPP1 & Maintenance of cell polarity, invasion, cell division. & $\begin{array}{l}\text { Paroxysmal nocturnal haemoglobinuria, idiopathic } \\
\text { ataxia, etc. }\end{array}$ & {$[62,63]$} \\
\hline MPP5 & Maintenance of cell polarity, cell proliferation. & Prostate cancer & [64] \\
\hline MPP2-7 & Maintenance of cell polarity, cell proliferation, synapse formation. & etinal disease, etc. & {$[23,65]$} \\
\hline $\mathrm{ZO}$ & Maintenance of cell polarity, tight junction, cell migration. & Cancer, kidney disease, etc. & {$[66,67]$} \\
\hline DGL5 & $\begin{array}{l}\text { Maintenance of cell polarity, cell proliferation, invasion and migration, cell } \\
\text { division. }\end{array}$ & $\begin{array}{l}\text { Breast and prostate cancer, Crohn's disease, } \\
\text { inflammatory bowel disease, etc. }\end{array}$ & {$[20,22,46,49]$} \\
\hline CARMA & Cell proliferation, inflammation, apoptosis, and metastasis. & Breast and ovarian cancer, etc. & {$[68,69]$} \\
\hline CACNB & Calcium- and potassium-channel & Patent ductus arteriosus & [70] \\
\hline MAGI & Maintenance of cell polarity, invasiveness, synapse formation, apoptosis. & Human hepatocellular carcinoma cells & {$[23,71]$} \\
\hline
\end{tabular}


DLG5 is a notable member of MAGUKs; it has evolved in the same manner as DLG1 and ZO1. Just like DLG1 and ZO1, DLG5 plays important roles in epithelial cell polarity maintenance, precursor cell division, cell proliferation, cell migration and invasion, and transmission of extracellular signals to the membrane and cytoskeleton. Numerous researchers have focused on the study of the roles of DLG5 in inflammatory bowel disease (IBD) and Crohn's disease $(\mathrm{CD})$ and their findings have been reviewed previously [20]. Here, we will review the functions of DLG5 in epithelial cell polarity maintenance and cancer development.

\section{DLG5 has evolved in the same manner as DLG1 and ZO1}

MAGUKs have evolved from a catalytically active GUK encoding gene. PDZ and SH3 domains gradually occur during their evolution. MPP and CACNB are first branched off, followed by the branching-off of DLG, ZO and CARMA subfamilies after duplication of the PDZ domain. DLG5 is formed when an additional PDZ domain is duplicated (Fig. 1) [10]. According to the evolution process of MAGUKs, DLG5, ZO and classical DLG proteins have similar structures. All of them contain a SH3 domain and a GUK domain (Fig. 2). Additionally, DLG5 contains a CARD domain, a DUF domain, a coiled-coil domain, and 4 PDZ domains [21, 22]; DLG1 has an additional L27 domain and 3 PDZ domains; the ZO subfamily has a unique ZU5 domain and 3 PDZ domains $[9,23]$. Maintenance of epithelial cell polarity and cell-cell junctions is a characteristic property of PDZ domain-containing proteins. $\mathrm{SH} 3$ domain can recognize the proline-rich sequence PXXP of cytoskeletal elements and signaling proteins [24]. The GUK domains of DLG5, DLG1 and ZO1 all contain GMP-binding pockets; however, the GUK domain of DLG1 has phosphor-peptide-binding modules, which play roles in diverse cellular processes by interacting with proteins, such as mitotic spindle regulatory protein LDN [25]. ZO1 and DLG5 lack residues essential for phosphate recognition in their GUK domain [11]. Studies have revealed that DLG5, DLG1 and ZO1 have similar functions in cell polarity maintenance and cancer development, which we assume may be due to the similarities in their structures.

\section{DLG5 in cell polarity maintenance}

\section{DLG5 participates in epithelial polarity maintenance by ensuring delivery of cadherins}

DLG5 contains 4-PDZ domains, and therefore, may participate in maintenance of epithelia cell polarity. N-cadherin is a component of the junctional complex and synthesized in Golgi. Newly synthesized $\mathrm{N}$-cadherin quickly binds to $\beta$-catenin and is delivered from Golgi to plasma membrane via secretory vesicles. Efficient and targeted delivery of $\mathrm{N}$-cadherin requires a SNARE-dependent fusion of $\mathrm{N}$-cadherin- $\beta$-catenin-containing vesicles with $\mathrm{AJ}$ proteins [26]. DLG5 interacts with $\beta$-catenin [27] and binds to syntaxin 4 , a component of t-SNARE complex. Thus, DLG5 acts as a linker between cadherin-catenin-carrying transport vesicles and t-SNARE complex at plasma membrane and promotes targeted delivery of cadherin. Loss of DLG5 will reduce in the level of cell-surface $\mathrm{N}$-cadherin, resulting in mislocalization and disorganization of AJ proteins, subsequent loss of cell polarity, cell adhesion, and ultimately, failure of epithelial maintenance [22]. The above review shows that DLG5 can maintain epithelial cell polarity by interacting with AJ proteins and promoting delivery of $\mathrm{N}$-cadherin to plasma membrane (Fig 3A, B).

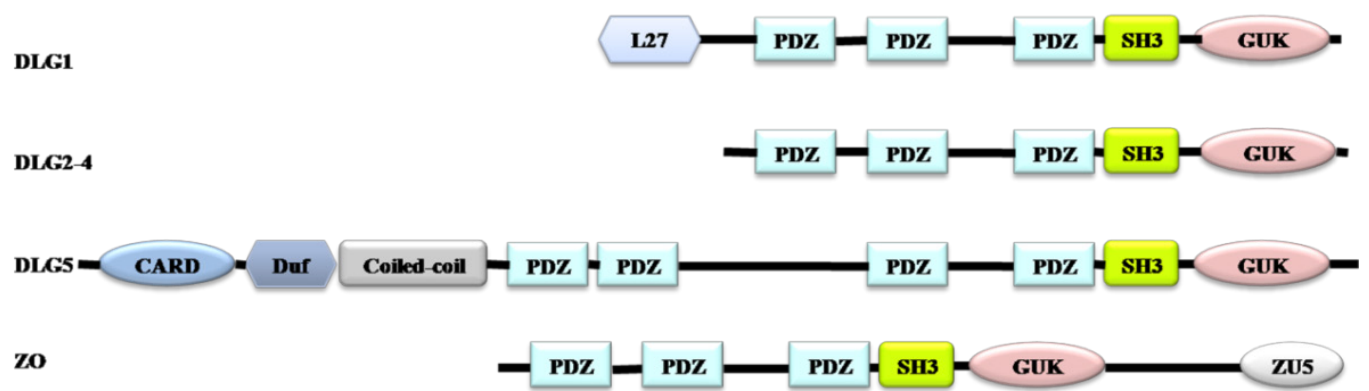

Figure 2. Domain architectures of DLG I, DLG2-4, DLG5 and ZO. All proteins have the PDZ, SH3 and GUK domains. DLGI has an additional L27 domain, ZO has a unique ZU5 domain, and DLG5 has a CARD domain, a DUF domain, a Coiled-coil domain, and four PDZ domains. 

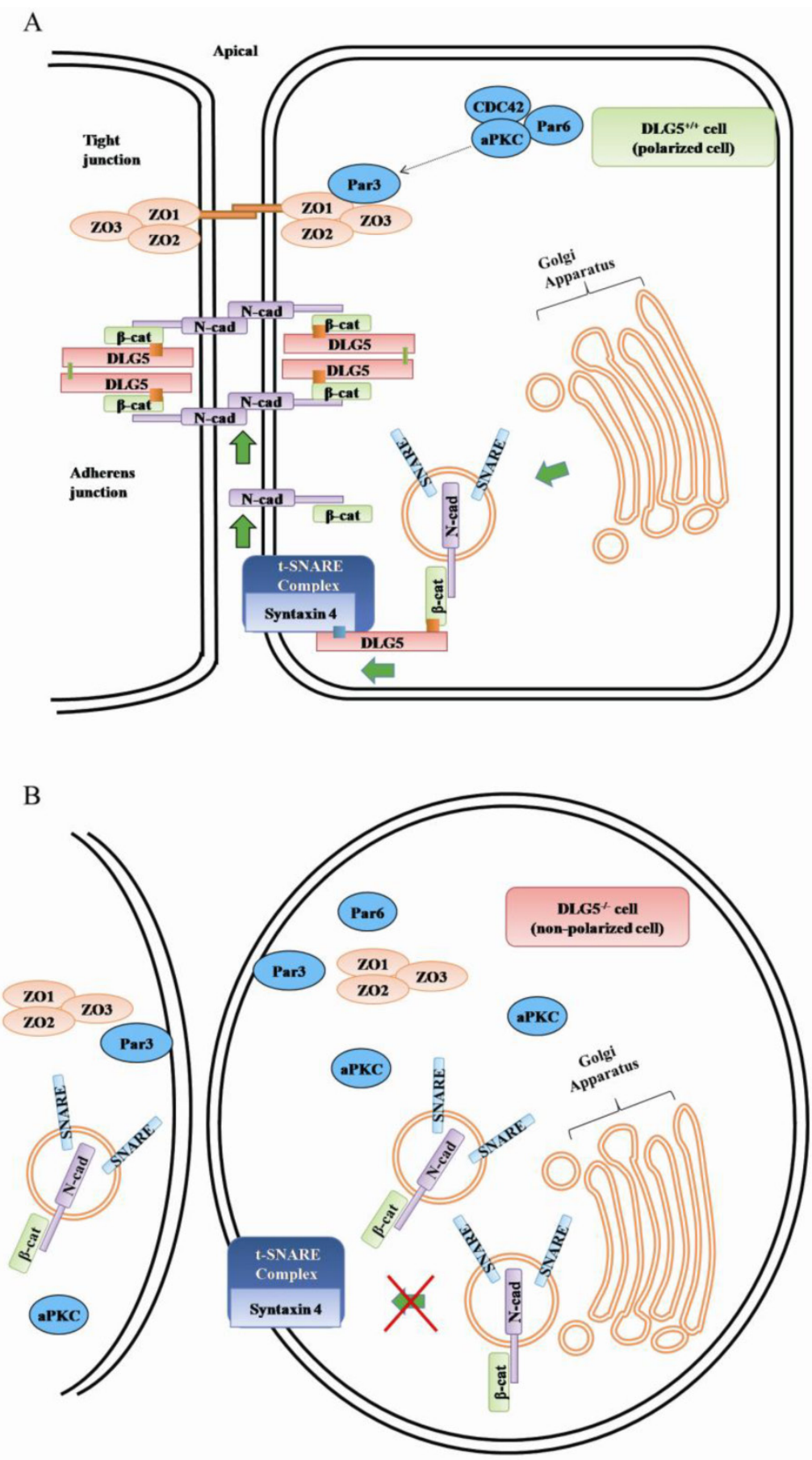

C

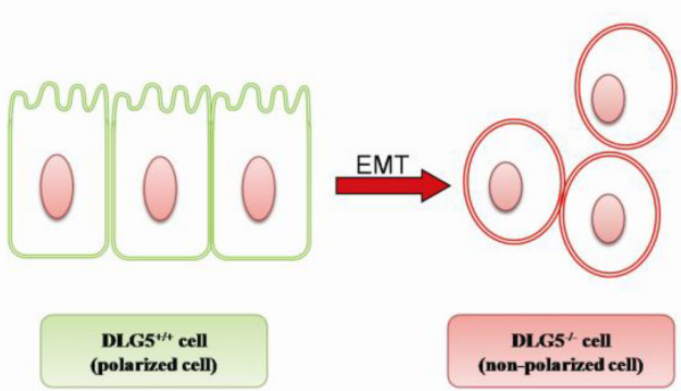

Figure 3. The working model of DLG5 in cell polarity maintenance and cancer development. A. in normal cell (DLG5 $5^{+/+}$cell); B in DLG5 $5^{-/-}$cell; C. loss of DLG5 induces EMT. 


\section{DLG5 stabilizes adherens and tight junction complexes}

DLG5 contains a unique coiled-coil domain at the N-terminus. Self-association is an interesting function of coiled-coil domains. Additionally, PDZ3-PDZ4 and SH3-GUK domains of DLG5 also have self-association potential and can bind to the $\mathrm{N}$-terminus of DL5 [22]. The characteristics of the coiled coil, PDZ3-PDZ4 and SH3-GUK domains suggest that DLG5 can self-associate and form a large protein complex containing multiple $\beta$-cateninbinding domains. Since DLG5 can interact with $\mathrm{N}$-cadherin and $\beta$-catenin of apical junctional adhesion complexes, the protein complex formed by DLG5 oligomerization can scaffold and stabilize cadherin-catenin adhesion complexes at the plasma membrane [22].

The component of the PAR complex, aPKC, is apically localized and participates in maintenance of apical-lateral polarity. aPKC can recruit the PAR3-PAR6 complex from tight junction sites to subapical region; as a result, PAR3 is excluded from tight junction sites, allowing for tight junction formation [28]. ZO1, located on the plasma membrane surface at sites of the cell-cell junction [29], is a well-known organizer for tight junction and notable epithelial marker [30]. ZO1 interacts with ZO2 and $\mathrm{ZO} 3$ via their PDZ2 domains to form a tight junctional complex. DLG5 participates in regulation of cell polarity by promoting the apical localization of aPKC [31]. It has been found that aPKC and ZO1 are mislocalized, while PAR3 and remains apically localized in DLG5 knockout mice [22, 31]. Therefore, loss of DLG5 may mislocalize ZO1 by inducing loss of the apically location of aPKC and retention of PAR3 at tight junction, then destabilizes the tight junctional complex, and eventually gives rise to the disorder of the tight junction (Fig 3 A, B). Together, DLG5 maintains epithelial polarity mainly by keeping the stability of tight junction and adherens junction.

\section{DLG5 affects cell division and cell fate via maintenance of apical-basal polarity}

DLG1 is a component of the SCRIB-LGL-DLG complex, and it functions to maintain the basal polarity of epithelial cells [32-34]. Another interesting function of DLG1 is that it participates in cell division. DLG1 mediates the cortical protein polarity by regulating the LGL localization, orients the spindles along the apical-basal axis by interacting with Leu-Gly-Asn repeat-enriched protein (LGN) at the GK domain [35-37], and creates intrinsic differences between daughter cells in mitotic neuroblasts [17].
DLG5 shows high homology to DLG1. They both contain 3-PDZ domains, a SH3 domain and a GK domain (Fig. 2). Therefore, DLG5 is also involved in maintenance of the polarity of proteins essential to cell division. Citron kinase (Citk) is highly polarized in neural progenitors and is essential to neurogenic cell division at the ventricular surface of the lateral ventricles in the central nervous system [38]. It has been found that Citk fails to polarize in mitotic neuronal precursors in DLG5 knockout mice, indicating that DLG5 is essential for Citk polarization. Therefore, DLG5 localizes cell divisions to the surface of the lateral ventricles by maintaining the polarity of Citk, which is essential to neurogenic cytokinesis [39]. DLG5 also mediates branching morphogenesis and progenitor differentiation by regulating atypical protein kinase $\mathrm{C}(\mathrm{aPKC})$, a component of apical polarity complexes [31]. Taken together, DLG5 and DLG1 can regulate cell division and cell fate via maintenance of apical-basal polarity.

\section{DLG5 in cancer development}

Cell polarity is a crucial phenomenon contributing to integrity and development of normal tissues and asymmetrical distribution of proteins. Loss of cell polarity may induce tissue disorganization and contribute to tumorigenesis. In other words, loss of cell polarity is a precondition and hallmark for cancer occurrence and development [40]. Does DLG5, which plays a role in maintenance of epithelial cells polarity, have a role in cancer development? The question will be answered in the following review.

\section{DLG5 is closely correlated with progression of cancer}

DLG, ZO1 and ZO2 were first identified as tumor suppressors in Drosophila [41]. Human DLG1 gene often undergoes mutations at conserved positions in mammary ductal carcinomas and its expression reduces in solid tumors [42-44]. Similarly, DLG5 is highly expressed in normal tissues, but its expression is diminished or lost in cancer cell lines [45]. Down-regulation of DLG5 is highly correlated with the stage of tumor [46]. The DLG5 expression is the lowest in basal-type [47] and metaplastic cancer cells [48], which shows epithelial-mesenchymal transitions (EMT) (Fig. 3C), stem cell-like characteristics and poor prognosis. DLG5 is also involved in carcinogenesis [49]. Knockdown of DLG5 induces EMT in cancer cells by affecting the expressions of epithelial/mesenchymal marker proteins, for example, by facilitating the expressions of the mesenchmal markers fibronectin and a-smooth muscle actin and by suppressing the expression of the epithelial marker E-cadherin $[50,51]$. Based on the above review, we 
speculate that DLG5 may be closely correlated with progression of cancer.

\section{DLG5 inhibits cell proliferation and migration}

Sustaining proliferative signaling and activating invasion and metastasis are two recognized hallmarks of cancer [52]. In Drosophila, over-proliferation of cancer cells may be the result of mutation in the $\mathrm{SH} 3$ domain of DLG $[34,53]$. In mammalian cells, overexpression of DLG1 impairs G1-S phase progression and inhibits cell proliferation by DLG1 binding to APC and PTEN [54]. Similarly, DLG5 may suppress cell proliferation by combining with p55 (also a member of MAGUKs containing four internal T/S-X-V motifs at C-terminal) via their PDZ domains to form a complex at the plasma membrane [45]. It has been found that overexpression of DLG5 is involved in pancreatic caricinogenesis by significantly suppressing the growth of pancreatic ductal adenocatcinoma (PDAC) cells [49]. The role of DLG5 in invasion and metastasis has also been reported. In breast cancer, overexpression of DLG5 inhibits cell migration, and knockdown of DLG5 induces cell migration via activation of the ERK signaling pathway [46]. All these reports indicate that DLG5 plays a role in cancer proliferation, migration, and cancer development.

\section{Conclusion and future directions}

DLG5 maintains epithelial polarity by ensuring the delivery and stabilization of junctional proteins and interacting with other polarity proteins such as $\mathrm{N}$-cadherin and $\beta$-catenin. DLG5 also participates in cell division and cell fate determination.

DLG5 may serve as a tumor suppressor. Knockdown of DLG5 can induce loss of epithelial polarity and promote cancer development, cell proliferation, invasiveness and metastasis. In breast cancer cells, DLG5 participates in progestin-induced growth inhibition and differentiation and is considered a primary progesterone target gene. This suggests that DLG5 may be used as a target gene in cancer therapy. To validate the role of DLG5 in cancer therapy, the relationship between DLG5 and progesterone receptor (PR) should be investigated [55].

The transforming growth factor- $\beta$ (TGF- $\beta$ ) can suppress the expression of DLG5 and the reduced expression of DLG5 will enhance EMT induced by TGF- $\beta$ receptor signaling and promote cancer progression [51]. Meanwhile, DLG5 can interact with TGF- $\beta$ receptors (T $\beta R s)$ and promote their degradation [56]. These findings indicate that DLG5 may participate in cancer progression via regulation of the TGF- $\beta$ receptor signaling pathway. In addition, downregulation of DLG5 is associated with overexpression of YAP (Yes-associated protein), a protein containing PDZ binding domain [46]. YAP has been proved to be an oncogene, whose dephosphorylation may activate the Hippo signal pathway and promote cancer cell proliferation $[57,58]$. Based on the above review, new questions arise: Can DLG5 regulate activation of the Hippo signal pathway? Does DLG5 inhibit cancer development via the YAP-Hippo pathway? In-depth research need to be conducted to reveal the role of DLG5 in tumorigenesis as soon as possible.

Together, DLG5 plays important roles in epithelial polarity maintenance and cancer development; it may a potential target for tumor molecular therapy. The DLG5-/- mice may make a significant contribution to research on pathogenesis of cancer and clinical drugs for cancer.

\section{Acknowledgement}

This work was financially supported by the National Natural Science Foundation of China (No. 81272342) and Program for New Century Excellent Talents, Ministry of Education of China (No.NCET-10-0677).

\section{Competing Interests}

The authors have declared that no competing interest exists.

\section{References}

1. Martin-Belmonte F,Perez-Moreno M. Epithelial cell polarity, stem cells and cancer. Nat Rev Cancer. 2012; 12: 23-38.

2. Niessen C M,Gottardi C J. Molecular components of the adherens junction. Biochim Biophys Acta. 2008; 1778: 562-71.

3. Tsukita S, Yamazaki Y, Katsuno T, et al. Tight junction-based epithelial microenvironment and cell proliferation. Oncogene. 2008; 27: 6930-8.

4. Moreno-Bueno G, Portillo F,Cano A. Transcriptional regulation of cell polarity in EMT and cancer. Oncogene. 2008; 27: 6958-69.

5. Jeanes A, Gottardi C J,Yap A S. Cadherins and cancer: how does cadherin dysfunction promote tumor progression? Oncogene. 2008; 27: 6920-9.

6. Gonzalez-Mariscal L, Lechuga S,Garay E. Role of tight junctions in cell proliferation and cancer. Prog Histochem Cytochem. 2007; 42: 1-57.

7. Coradini D, Casarsa C,Oriana S. Epithelial cell polarity and tumorigenesis: new perspectives for cancer detection and treatment. Acta Pharmacol Sin. 2011; 32: 552-64.

8. Sheng M,Sala C. PDZ domains and the organization of supramolecular complexes. Annu Rev Neurosci. 2001; 24: 1-29.

9. de Mendoza A, Suga H,Ruiz-Trillo I. Evolution of the MAGUK protein gene family in premetazoan lineages. BMC Evol Biol. 2010; 10: 93.

10. te Velthuis A J, Admiraal J F,Bagowski C P. Molecular evolution of the MAGUK family in metazoan genomes. BMC Evol Biol. 2007; 7: 129.

11. Zhu J, Shang Y, Xia C, et al. Guanylate kinase domains of the MAGUK family scaffold proteins as specific phospho-protein-binding modules. EMBO J. 2011; 30: 4986-97.

12. Funke L, Dakoji S,Bredt D S. Membrane-associated guanylate kinases regulate adhesion and plasticity at cell junctions. Annu Rev Biochem. 2005; 74: 219-45.

13. Alie A,Manuel $\mathrm{M}$. The backbone of the post-synaptic density originated in a unicellular ancestor of choanoflagellates and metazoans. BMC Evol Biol. 2010; 10: 34 .

14. Goode S,Perrimon N. Inhibition of patterned cell shape change and cell invasion by Discs large during Drosophila oogenesis. Genes Dev. 1997; 11: 2532-44.

15. Subbaiah V K, Narayan N, Massimi P, et al. Regulation of the DLG tumor suppressor by beta-catenin. Int I Cancer. 2012; 131: 2223-33.

16. Massimi P, Gammoh N, Thomas M, et al. HPV E6 specifically targets different cellular pools of its PDZ domain-containing tumour suppressor substrates for proteasome-mediated degradation. Oncogene. 2004; 23: 8033-9.

17. Ohshiro T, Yagami T, Zhang C, et al. Role of cortical tumour-suppressor proteins in asymmetric division of Drosophila neuroblast. Nature. 2000; 408: $593-6$ 
18. Tsukita $S$, Katsuno $T$, Yamazaki $Y$, et al. Roles of ZO-1 and ZO-2 in establishment of the belt-like adherens and tight junctions with paracellular permselective barrier function. Ann N Y Acad Sci. 2009; 1165: 44-52.

19. Ito S, Miyashita H, Suzuki $Y$, et al. Enhanced cancer metastasis in mice deficient in vasohibin-1 gene. PLoS One. 2013; 8: e73931.

20. Friedrichs F,Stoll M. Role of discs large homolog 5. World J Gastroenterol. 2006; 12: 3651-6.

21. Friedrichs F, Henckaerts L, Vermeire S, et al. The Crohn's disease susceptibility gene DLG5 as a member of the CARD interaction network. J Mol Med (Berl). 2008; 86: 423-32.

22. Nechiporuk T, Fernandez T E,Vasioukhin V. Failure of epithelial tube maintenance causes hydrocephalus and renal cysts in Dlg5-/- mice. Dev Cell. 2007; 13: 338-50.

23. Zheng C Y, Seabold G K, Horak M, et al. MAGUKs, synaptic development, and synaptic plasticity. Neuroscientist. 2011; 17: 493-512.

24. Ren R, Mayer B J, Cicchetti P, et al. Identification of a ten-amino acid proline-rich SH3 binding site. Science. 1993; 259: 1157-61.

25. Sans N, Wang P Y, Du Q, et al. mPins modulates PSD-95 and SAP102 trafficking and influences NMDA receptor surface expression. Nat Cell Biol. 2005; 7: 1179-90.

26. Mary S, Charrasse S, Meriane $\mathrm{M}$, et al. Biogenesis of $\mathrm{N}$-cadherin-dependent cell-cell contacts in living fibroblasts is a microtubule-dependent kinesin-driven mechanism. Mol Biol Cell. 2002; 13: 285-301.

27. Watabe-Uchida $\mathrm{M}$, Uchida $\mathrm{N}$, Imamura $\mathrm{Y}$, et al. alpha-Catenin-vinculin interaction functions to organize the apical junctional complex in epithelial cells. J Cell Biol. 1998; 142: 847-57.

28. Morais-de-Sa E, Mirouse V,St Johnston D. aPKC phosphorylation of Bazooka defines the apical/lateral border in Drosophila epithelial cells. Cell. 2010; 141: 509-23.

29. Willott E, Balda M S, Fanning A S, et al. The tight junction protein ZO-1 is homologous to the Drosophila discs-large tumor suppressor protein of septate junctions. Proc Natl Acad Sci U S A. 1993; 90: 7834-8.

30. Zeisberg M,Neilson E G. Biomarkers for epithelial-mesenchymal transitions. J Clin Invest. 2009; 119: 1429-37.

31. Nechiporuk T, Klezovitch O, Nguyen L, et al. Dlg5 maintains apical aPKC and regulates progenitor differentiation during lung morphogenesis. Dev Biol. 2013.

32. Humbert P O, Grzeschik N A, Brumby A M, et al. Control of tumourigenesis by the Scribble/Dlg/Lgl polarity module. Oncogene. 2008; 27: 6888-907.

33. Yamanaka T,Ohno S. Role of $\mathrm{Lgl} / \mathrm{Dlg} /$ Scribble in the regulation of epithelial junction, polarity and growth. Front Biosci. 2008; 13: 6693-707.

34. Wodarz A. Tumor suppressors: linking cell polarity and growth control. Curr Biol. 2000; 10: R624-6.

35. Siegrist S E,Doe C Q. Microtubule-induced Pins/Galphai cortical polarity in Drosophila neuroblasts. Cell. 2005; 123: 1323-35.

36. Johnston C A, Hirono K, Prehoda K E, et al. Identification of an Aurora-A/PinsLINKER/Dlg spindle orientation pathway using induced cell polarity in S2 cells. Cell. 2009; 138: 1150-63.

37. Bergstralh D T, Lovegrove H E,St Johnston D. Discs large links spindle orientation to apical-basal polarity in Drosophila epithelia. Curr Biol. 2013; 23: 1707-12.

38. Sarkisian M R, Li W, Di Cunto F, et al. Citron-kinase, a protein essential to cytokinesis in neuronal progenitors, is deleted in the flathead mutant rat. J Neurosci. 2002; 22: RC217.

39. Chang $\mathrm{Y}$, Klezovitch $\mathrm{O}$, Walikonis $\mathrm{R} \mathrm{S}$, et al. Discs large 5 is required for polarization of citron kinase in mitotic neural precursors. Cell Cycle. 2010; 9: 1990-7.

40. Ellenbroek S I, Iden S,Collard J G. Cell polarity proteins and cancer. Semin Cancer Biol. 2012; 22: 208-15.

41. Watson K L, Justice R W,Bryant P J. Drosophila in cancer research: the first fifty tumor suppressor genes. J Cell Sci Suppl. 1994; 18: 19-33.

42. Watson R A, Rollason T P, Reynolds G M, et al. Changes in expression of the human homologue of the Drosophila discs large tumour suppressor protein in high-grade premalignant cervical neoplasias. Carcinogenesis. 2002; 23: 1791-6.

43. Lin H T, Steller M A, Aish L, et al. Differential expression of human Dlg in cervical intraepithelial neoplasias. Gynecol Oncol. 2004; 93: 422-8.

44. Fuja T J, Lin F, Osann K E, et al. Somatic mutations and altered expression of the candidate tumor suppressors CSNK1 epsilon, DLG1, and EDD/hHYD in mammary ductal carcinoma. Cancer Res. 2004; 64: 942-51.

45. Nakamura H, Sudo T, Tsuiki $H$, et al. Identification of a novel human homolog of the Drosophila dlg, P-dlg, specifically expressed in the gland tissues and interacting with p55. FEBS Lett. 1998; 433: 63-7.

46. Smolen G A, Zhang J, Zubrowski M J, et al. A genome-wide RNAi screen identifies multiple RSK-dependent regulators of cell migration. Genes Dev. 2010; 24: 2654-65.

47. Sarrio D, Rodriguez-Pinilla S M, Hardisson D, et al. Epithelial-mesenchymal transition in breast cancer relates to the basal-like phenotype. Cancer Res. 2008; 68: 989-97.

48. Hennessy B T, Gonzalez-Angulo A M, Stemke-Hale K, et al. Characterization of a naturally occurring breast cancer subset enriched in epithelial-to-mesenchymal transition and stem cell characteristics. Cancer Res. 2009; 69: 4116-24.

49. Taniuchi $K$, Nakagawa $H$, Nakamura $T$, et al. Down-regulation of RAB6KIFL/KIF20A, a kinesin involved with membrane trafficking of discs large homologue 5, can attenuate growth of pancreatic cancer cell. Cancer Res. 2005; 65: 105-12

50. Wakabayashi M, Ito T, Mitsushima M, et al. Interaction of lp-dlg/KIAA0583, a membrane-associated guanylate kinase family protein, with vinexin and beta-catenin at sites of cell-cell contact. J Biol Chem. 2003; 278: 21709-14.

51. Sezaki T, Inada K, Sogabe T, et al. Role of Dlg5/lp-dlg, a membrane-associated guanylate kinase family protein, in epithelial-mesenchymal transition in LLc-PK1 renal epithelial cells. PLoS One. 2012; 7: e35519.

52. Hanahan D,Weinberg R A. Hallmarks of cancer: the next generation. Cell. 2011; 144: 646-74.

53. Woods D F, Hough C, Peel D, et al. Dlg protein is required for junction structure, cell polarity, and proliferation control in Drosophila epithelia. J Cell Biol. 1996; 134: 1469-82.

54. Ishidate $\mathrm{T}$, Matsumine A, Toyoshima $\mathrm{K}$, et al. The APC-hDLG complex negatively regulates cell cycle progression from the G0/G1 to $S$ phase. Oncogene. 2000; 19: 365-72.

55. Purmonen S, Ahola T M, Pennanen P, et al. HDLG5/KIAA0583, encoding a MAGUK-family protein, is a primary progesterone target gene in breast cancer cells. Int J Cancer. 2002; 102: 1-6.

56. Sezaki T, Tomiyama L, Kimura $\mathrm{Y}$, et al. Dlg5 interacts with the TGF-beta receptor and promotes its degradation. FEBS Lett. 2013; 587: 1624-9.

57. Sudol M, Shields D C,Farooq A. Structures of YAP protein domains reveal promising targets for development of new cancer drugs. Semin Cell Dev Biol. 2012; 23: 827-33

58. Zhao B, Lei Q Y,Guan K L. The Hippo-YAP pathway: new connections between regulation of organ size and cancer. Curr Opin Cell Biol. 2008; 20: 638-46.

59. Roberts S, Delury C,Marsh E. The PDZ protein discs-large (DLG): the 'Jekyll and Hyde' of the epithelial polarity proteins. FEBS J. 2012; 279: 3549-58.

60. Hosak L. New findings in the genetics of schizophrenia. World J Psychiatry. 2013; 3: 57-61.

61. Ahn S Y, Kim Y, Kim S T, et al. Scaffolding proteins DLG1 and CASK cooperate to maintain the nephron progenitor population during kidney development. J Am Soc Nephrol. 2013; 24: 1127-38.

62. Alahmad A, Preuss K D, Schenk J, et al. Desmoplakin and KIF20B as target antigens in patients with paroxysmal nocturnal haemoglobinuria. $\mathrm{Br} \mathrm{J}$ Haematol. 2010; 151: 273-80.

63. Fritzler M J, Kerfoot S M, Feasby T E, et al. Autoantibodies from patients with idiopathic ataxia bind to M-phase phosphoprotein-1 (MPP1). J Investig Med. 2000; 48: 28-39.

64. Teles Alves I, Hartjes T, McClellan E, et al. Next-generation sequencing reveals novel rare fusion events with functional implication in prostate cancer. Oncogene. 2014

65. Stohr H, Stojic J,Weber B H. Cellular localization of the MPP4 protein in the mammalian retina. Invest Ophthalmol Vis Sci. 2003; 44: 5067-74.

66. Itoh $\mathrm{M}$, Furuse $\mathrm{M}$, Morita $\mathrm{K}$, et al. Direct binding of three tight junction-associated MAGUKs, ZO-1, ZO-2, and ZO-3, with the $\mathrm{COOH}$ termini of claudins. J Cell Biol. 1999; 147: 1351-63.

67. Gonzalez-Mariscal L, Bautista P, Lechuga S, et al. ZO-2, a tight junction scaffold protein involved in the regulation of cell proliferation and apoptosis. Ann N Y Acad Sci. 2012; 1257: 133-41.

68. Wang X,Roberts C W. CARMA: CARM1 methylation of SWI/SNF in breast cancer. Cancer Cell. 2014; 25: 3-4.

69. Sun J. CARMA3: A novel scaffold protein in regulation of NF-kappaB activation and diseases. World J Biol Chem. 2010; 1: 353-61.

70. Waleh N, Hodnick R, Jhaveri N, et al. Patterns of gene expression in the ductus arteriosus are related to environmental and genetic risk factors for persistent ductus patency. Pediatr Res. 2010; 68: 292-7.

71. $\mathrm{Li} \mathrm{X,} \mathrm{Li} \mathrm{Z,} \mathrm{Li} \mathrm{N,} \mathrm{et} \mathrm{al.} \mathrm{MAGI2} \mathrm{enhances} \mathrm{the} \mathrm{sensitivity} \mathrm{of} \mathrm{BEL-7404} \mathrm{human}$ hepatocellular carcinoma cells to staurosporine-induced apoptosis by increasing PTEN stability. Int J Mol Med. 2013; 32: 439-47. 